\title{
1958-2014: After 56 Years of Research, Cytochrome P450 Reactivity Is Finally Explained
}

\author{
Ashley B. McQuarters, Matthew W. Wolf, Andrew P. Hunt, and Nicolai Lehnert*
}

$\mathrm{C}-\mathrm{H}$ bond activation . Cytochrome P450 .

hydroxylation $\cdot$ monooxygenases

$C$ P450 enzymes (Cyt. P450s) play a key role in the synthesis of essential biomolecules, the metabolism of pharmaceutical drugs, and the detoxification of xenobiotics. The most ubiquitous form of Cyt. P450s are monooxygenases, which hydroxylate substrates following the reaction: $:^{[1]}$

$\mathrm{R}-\mathrm{H}+\mathrm{O}_{2}+\mathrm{NAD}(\mathrm{P}) \mathrm{H}+\mathrm{H}^{+} \rightarrow \mathrm{R}-\mathrm{OH}+\mathrm{NAD}(\mathrm{P})^{+}+\mathrm{H}_{2} \mathrm{O}$

The active sites of Cyt. P450s contain a single heme $b$ cofactor with a proximal cysteinate ligand. Figure 1 shows the active site of P. putida Cyt. P450cam as an example. The catalytic mechanism of Cyt. P450s has been studied in detail and is depicted in Figure 1. ${ }^{[1]}$ After one-electron reduction of the heme, $\mathrm{O}_{2}$ is bound first and subsequently reduced and protonated, generating an $\mathrm{Fe}^{\mathrm{III}}-\mathrm{OOH}$ complex (Compound 0 ). Protonation of this species results in heterolytic $\mathrm{O}-\mathrm{O}$ bond cleavage, producing the critical intermediate Compound $\mathrm{I}$ and $\mathrm{H}_{2} \mathrm{O}$. Compound $\mathrm{I}$ is able to abstract a hydrogen atom from the substrate resulting in an $\mathrm{Fe}^{\mathrm{IV}}$ $\mathrm{OH}$ complex (Compound II) and a carbon-based substrate radical, according to the "rebound" mechanism. ${ }^{[1,2 c]}$ The carbon-based radical is finally hydroxylated to complete the catalytic cycle.

Although Cyt. P450 enzymes have been studied for the past 56 years, key questions have remained with respect to the nature of Compound I, its ability to oxidize substrates, and the role of the proximal thiolate ligand for catalysis. Progress in this regard has been stalled by the difficulty in trapping Compound I, which is usually short-lived and generated only in low yield. ${ }^{[2 a, b]}$ Recently, however, Green and co-workers obtained Compound I in high yield $(\approx 75 \%)$ for the first time by reacting a thermophilic Cyt. P450 (CYP119) in its ferric oxidation state with meta-chloroperoxybenzoic acid $(m$ CPBA). ${ }^{[3 a]}$ The UV/Vis spectrum of this species, which is stable in solution for roughly $35 \mathrm{~ms}$, exhibits the Soret band at $367 \mathrm{~nm}$ and Q bands at 610 and $690 \mathrm{~nm}$ (Figure 2). Rapidfreeze quench Mössbauer spectroscopy of this intermediate shows isomer shifts and quadrupole splitting values $(\delta=$ $0.11 \mathrm{~mm} \mathrm{~s}^{-1}$ and $\Delta E_{\mathrm{Q}}=0.90 \mathrm{~mm} \mathrm{~s}^{-1}$ ) similar to those of Compound I of chloroperoxidase (CPO),${ }^{[4]}$ confirming the

[*] A. B. McQuarters, M. W. Wolf, A. P. Hunt, Dr. N. Lehnert Department of Chemistry, University of Michigan 930 N. University, Ann Arbor, MI 48109 (USA)

E-mail: lehnertn@umich.edu

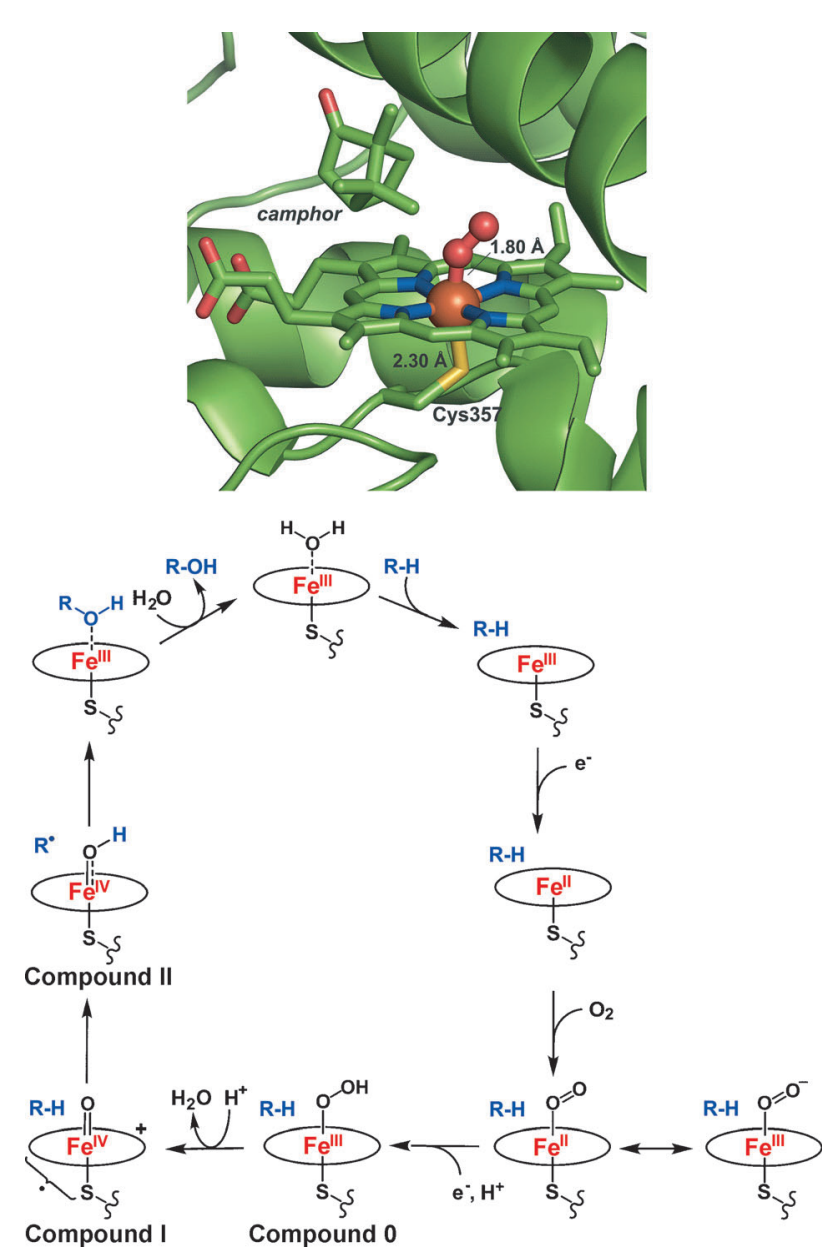

Figure 1. Top: $\mathrm{O}_{2}$ bound to the ferrous heme in the active site of Cyt. P450cam from P. putida (PDB code 1DZ9). Bottom: The catalytic cycle of Cyt. P450 monooxygenases (where R-H is the substrate).

$\mathrm{Fe}^{\mathrm{IV}}$ oxidation state of iron. The EPR spectrum of Compound $\mathrm{I}$ exhibits $\mathrm{g}_{\perp}$ values of 1.86 and 1.96 and $\mathrm{g}_{\|}=2.0$, which is indicative of an $S=1 / 2$ system. This suggests that the $\mathrm{Fe}^{\mathrm{IV}}=\mathrm{O}$ unit $(S=1)$ in this species is antiferromagnetically coupled to the porphyrin-based radical $(S=1 / 2)$, leading to a doublet $(S=$ $1 / 2$ ) ground state for Compound $I^{[3 a]}$ These findings are in agreement with the results of DFT and QM/MM calculations. $^{[5]}$ 


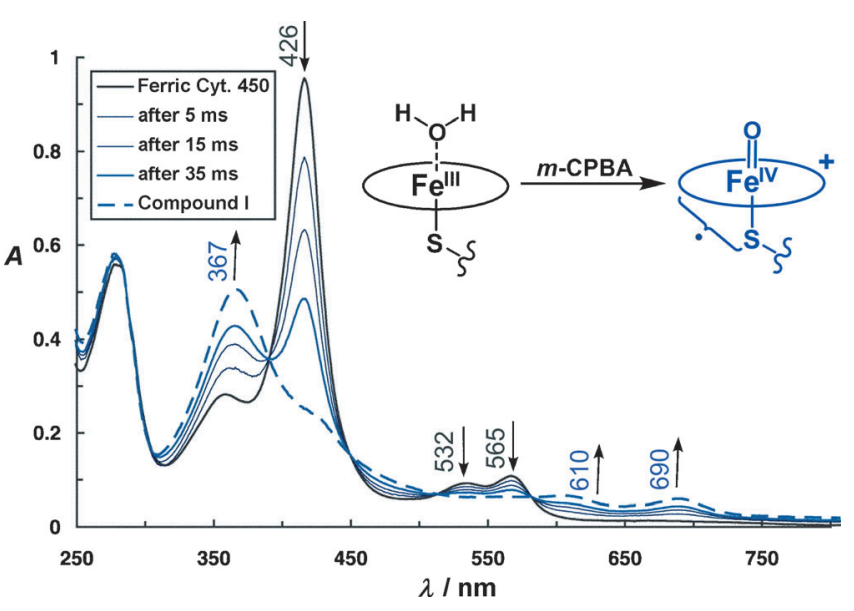

Figure 2. UV/Vis spectrum of ferric Cyt. P450 (black) and spectral changes upon the addition of $m$-CPBA (blue, dashed) at different time points (adapted from reference [3a]). Reprinted with permission from AAAS.

After reaction of Compound I with a substrate having a $\mathrm{C}-\mathrm{H}$ bond, an $\mathrm{Fe}^{\mathrm{IV}}-\mathrm{OH}$ intermediate, Compound II, is created (see Figure 1). Green and co-workers stabilized this intermediate using a unique Cyt. P450 (CYP158) that has a large, solvent-exposed active site. ${ }^{[3 \mathrm{~b}]}$ The $\mathrm{Fe}^{\mathrm{IV}}-\mathrm{OH}$ complex was generated in greater than $90 \%$ yield (at $\mathrm{pH} 9$; decaying at $\approx 0.01 \mathrm{~s}^{-1}$ ) by the reaction of the ferric heme protein with $m$ CPBA. The UV/Vis spectrum of Compound II has a split Soret band at 370 and $426 \mathrm{~nm}$ and $\mathrm{Q}$ bands at 532 and $565 \mathrm{~nm}$, which is indicative of a six-coordinate (6C) thiolate-ligated ferryl heme complex. The Mössbauer spectrum of this intermediate shows isomer shifts and quadrupole splittings $\left(\delta=0.1 \mathrm{~mm} \mathrm{~s}^{-1}\right.$ and $\left.\Delta E_{\mathrm{O}}=2.05 \mathrm{~mm} \mathrm{~s}^{-1}\right)$ similar to those of Compound II of CPO ${ }^{[6]}$ Additionally, iron K-edge X-ray absorption measurements further confirmed that Compound II is $6 \mathrm{C}$ and, importantly, that the iron center is in the ferryl oxidation state. ${ }^{[3 b]}$ These results demonstrate again (in agreement with previous studies) that Compound II in hemethiolate active sites is protonated at physiological $\mathrm{pH}^{[3 \mathrm{~b}, 6]}$

The radical rebound-type mechanism described above requires $\mathrm{H}$-atom abstraction by the metal-oxo unit. Mayer and co-workers have used linear free energy relationships to understand $\mathrm{H}$-atom abstraction in metal-oxo systems. ${ }^{[7]}$ It was shown that the driving force for $\mathrm{C}-\mathrm{H}$ bond activation $\left(\Delta G_{\mathrm{p}}\right)$ is related to the energy difference between the $\mathrm{O}-\mathrm{H}$ bond formed, $D(\mathrm{O}-\mathrm{H})$, and the $\mathrm{C}-\mathrm{H}$ bond broken, $D(\mathrm{C}-\mathrm{H}): \Delta G_{\mathrm{p}}=$ $D(\mathrm{C}-\mathrm{H})-D(\mathrm{O}-\mathrm{H})$.

For heme enzymes, $D(\mathrm{O}-\mathrm{H})$ is dependent on the oneelectron reduction potential of Compound $\mathrm{I}$ and the $\mathrm{p} K_{\mathrm{a}}$ of Compound II as shown in Equation (2) (where $C$ is a constant).$^{[7]}$ In other words, the thermodynamic driving force for $\mathrm{H}$-atom abstraction can originate from the redox potential or the basicity of the site, or a combination of both.

$$
D(\mathrm{O}-\mathrm{H})=23.06 E_{\text {Comp-I }}^{\circ}+1.37 \mathrm{p} K_{\text {aComp-II }}+C\left(\mathrm{kcal} \mathrm{mol}^{-1}\right)
$$

The reduction potential of the heme is largely dictated by the proximal ligand. For example, it was previously shown that a thiolate ligand can decrease the $\mathrm{Fe}^{\mathrm{II}} / \mathrm{Fe}^{\mathrm{III}}$ redox potential by up to $400 \mathrm{mV}$ compared to that of histidineligated proteins. ${ }^{[1]}$ This suggests that thiolate ligation actually reduces the driving force for $\mathrm{C}-\mathrm{H}$ activation that originates from the redox potential in Compound I. To understand how Equation (2) applies to $\mathrm{C}-\mathrm{H}$ bond activation by Compound I in Cyt. P450s, Green and co-workers undertook the tedious task of determining the basicity of Compound II by systematic $\mathrm{pH}$ variation [Eq. (3)]

$[\mathrm{Fe}(\mathrm{Porph})(\mathrm{Cys})(\mathrm{OH})]+$ Base $\rightarrow[\mathrm{Fe}(\mathrm{Porph})(\mathrm{Cys})(\mathrm{O})]^{-}+\mathrm{H}[\mathrm{Base}]^{+}$

The deprotonated $\mathrm{Fe}^{\mathrm{IV}}=\mathrm{O}$ complex is formed at roughly $\mathrm{pH} 14$ and retains its thiolate ligand, which is confirmed by UV/Vis and Mössbauer spectroscopy (Figure 3). From these
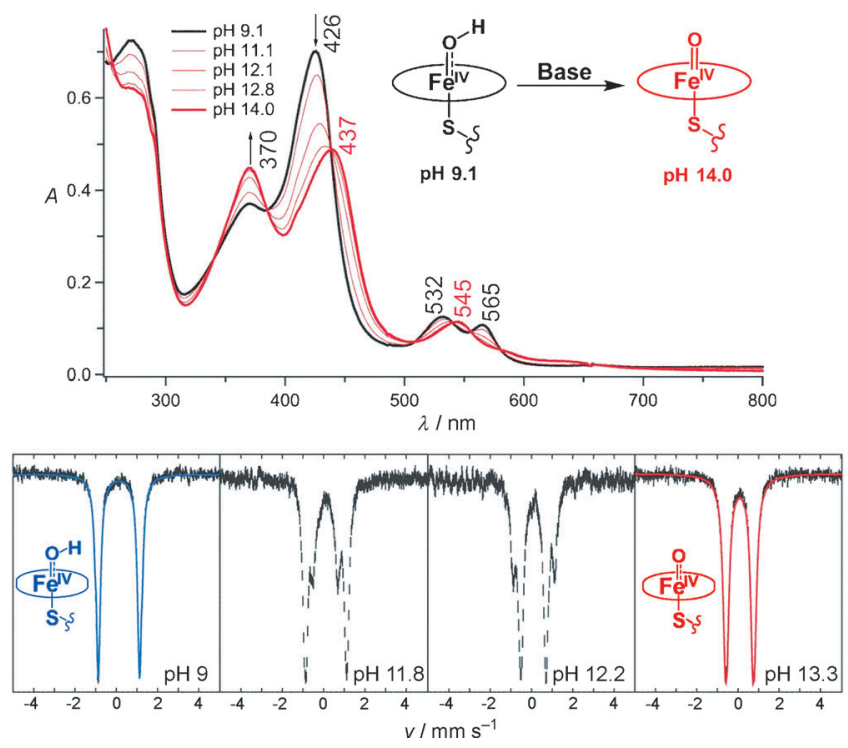

Figure 3. Top: UV/Vis spectra of Compound II (black) with increasing $\mathrm{pH}$ to form the corresponding $\mathrm{Fe}^{\mathrm{IV}}=\mathrm{O}$ complex (red). Bottom: the same experiment monitored by Mössbauer spectroscopy (Compound II, blue, $\mathrm{Fe}^{\mathrm{IV}}=\mathrm{O}$, red; adapted from reference [3b]). Reprinted with permission from AAAS.

experiments, the $\mathrm{p} K_{\mathrm{a}}$ of the $\mathrm{Fe}^{\mathrm{IV}}-\mathrm{OH}$ complex is estimated to be approximately $12 .^{[3 \mathrm{~b}]}$ Interestingly, this is about 9 times more basic than Compound II in histidine-ligated proteins $\left(\mathrm{p} K_{\mathrm{a}} \approx 3.5\right) .^{[1]}$ The basicity of Compound II is surprising, since $\mathrm{Fe}^{\mathrm{IV}}=\mathrm{O}$ units are electrophilic and rarely protonated. ${ }^{[4,6]}$ This emphasizes that the thiolate ligand is a stronger electron donor than histidine, and in turn makes the $\mathrm{Fe}^{\mathrm{IV}}-\mathrm{O}$ unit more basic. This demonstrates that much of the driving force for $\mathrm{C}-$ $\mathrm{H}$ activation by Compound $\mathrm{I}$ in Cyt. $\mathrm{P} 450$ s results from basicity, and not from a large (positive) redox potential of this intermediate. In this sense, the thiolate ligand "tames" the oxidative power of Compound I, without compromising the driving force for $\mathrm{C}-\mathrm{H}$ bond activation.

Interestingly, this finding parallels observations in Cyt. P450 nitric oxide reductase (P450nor), an enzyme found 
in soil-dwelling fungi and yeast that reduces nitric oxide (NO) to nitrous oxide $\left(\mathrm{N}_{2} \mathrm{O}\right)$ by the reaction:

$2 \mathrm{NO}+\mathrm{NAD}(\mathrm{P}) \mathrm{H}+\mathrm{H}^{+} \rightarrow \mathrm{N}_{2} \mathrm{O}+\mathrm{NAD}(\mathrm{P})^{+}+\mathrm{H}_{2} \mathrm{O}$

In the proposed mechanism of this enzyme, a ferric hemenitrosyl complex reacts with a hydride donor to form an $\mathrm{Fe}^{\mathrm{II}}$ NHO species. ${ }^{[\mathrm{aa}]}$ In the presence of an axial histidine ligand as in myoglobin $(\mathrm{Mb})$, the corresponding $\mathrm{Mb}^{\mathrm{II}}-\mathrm{NHO}$ adduct is stable and not further protonated. ${ }^{[9]}$ However, DFT calculations suggest that the $\mathrm{Fe}^{\mathrm{II}}-\mathrm{NHO}$ complex in $\mathrm{P} 450$ nor is basic enough to pick up an additional proton, resulting in a doubly protonated $\mathrm{Fe}^{\mathrm{IV}}-\mathrm{NHOH}^{-}$-type species. ${ }^{[8 \mathrm{~b}]}$ The formation of this intermediate is crucial for $\mathrm{P} 450$ nor catalysis as it activates the ferrous HNO complex to react with another molecule of NO, completing the catalytic cycle. Here, the presence of the axial thiolate ligand is responsible for the enhanced basicity of the HNO intermediate in Cyt. P450nor. Hence, in both the NOR and the monooxygenases, the donation from the thiolate ligand to the iron center is crucial for catalysis.

In summary, the recent efforts of the Green group in isolating and characterizing Compounds I and II of Cyt. P450s have provided key insights into the electronic structure and reactivity of these important intermediates, and in this way, have answered key questions with regards to the mechanism of Cyt. P450s. The high $\mathrm{p} K_{\mathrm{a}}$ of Compound II confirms the strong electron-donating nature of the thiolate ligand and provides the driving force for $\mathrm{C}-\mathrm{H}$ bond activation. The lowered oxidative power of Compound I in Cyt. P450s is a means to protect the enzyme from this reactive intermediate by preventing the fast oxidation of other amino acids in the proximity of the active site, and in this way, shutting down nonproductive and potentially destructive side reactions. In contrast, other heme proteins such as oxidases and peroxidases, which use Compound I to oxidize external substrates, are ligated by histidine residues, leading to a much more oxidizing Compound I, but a much less basic Compound II. This directly relates to the different functions of these enzymes. Whereas Cyt. P450s hydroxylate substrates that are directly bound in the active site, (per)oxidases oxidize substrates that in many cases are bound to the protein surface. Hence, in the latter cases a large driving force based on a large, positive redox potential is required, whereas the basicity of Compound IIcannot contribute to reactivity. This demonstrates again how wisely nature designs its catalysts, and optimizes the active sites to perfection in order to mediate a desired reaction.

Received: February 13, 2014

Published online: April 7, 2014

[1] P. R. Ortiz de Montellano, Cytochrome P450: structure, mechanism, and biochemistry, Kluwer Academic/Plenum, New York, 2005.

[2] a) T. Spolitak, J. H. Dawson, D. P. Ballou, J. Biol. Chem. 2005, 280, 20300-20309; b) D. G. Kellner, S.-C. Hung, K. E. Weiss, S. G. Sligar, J. Biol. Chem. 2002, 277, 9641 -9644; c) J. T. Groves, G. A. McClusky, J. Am. Chem. Soc. 1976, 98, 859-861.

[3] a) J. Rittle, M. T. Green, Science 2010, 330, 933-937; b) T. H. Yosca, J. Rittle, C. M. Krest, E. L. Onderko, A. Silakov, J. C. Calixto, R. K. Behan, M. T. Green, Science 2013, 342, 825-829.

[4] R. K. Behan, L. M. Hoffart, K. L. Stone, C. Krebs, M. T. Green, J. Am. Chem. Soc. 2006, 128, 11471-11474.

[5] J. C. Schöneboom, F. Neese, W. Thiel, J. Am. Chem. Soc. 2005, $127,5840-5853$.

[6] K. L. Stone, L. M. Hoffart, R. K. Behan, C. Krebs, M. T. Green, J. Am. Chem. Soc. 2006, 128, 6147-6153.

[7] J. J. Warren, T. A. Tronic, J. M. Mayer, Chem. Rev. 2010, 110, $6961-7001$.

[8] a) A. B. McQuarters, N. E. Wirgau, N. Lehnert, Curr. Opin. Chem. Biol. 2014, 19, 82-89; b) N. Lehnert, V. K. K. Praneeth, F. Paulat, J. Comput. Chem. 2006, 27, 1338-1351.

[9] R. Lin, P. J. Farmers, J. Am. Chem. Soc. 2000, 122, 2393-2394. 